\title{
Enhancement gain of broadband elliptical microstrip patch array antenna with mutual coupling for wireless communication
}

\author{
Ali Khalid Jassim, Raad H. Thaher \\ Electrical Engineering Department, Al Mustansiriyh University, Baghdad, Iraq
}

\begin{tabular}{l} 
Article Info \\
\hline Article history: \\
Received Aug 26, 2018 \\
Revised Nov 23, 2018 \\
Accepted Nov 15, 2018 \\
\hline Keywords: \\
Elliptical patch array antenna \\
Field configuration \\
Microstrip with triangle notch \\
SWR \\
The radiation pattern
\end{tabular}

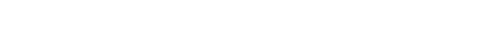

\section{Corresponding Author:}

Ali Khalid Jassim, Electrical Engineering Department, Al Mustansiriyh University, Baghdad, Iraq. Email: alijassim79@yahoo.com

\begin{abstract}
The paper presented analysis, design and manufacturing single optimize parameters of a new broadband elliptical patch antenna with microstrip center feed line and the array has been implemented to improve gain antenna. The antenna array dimension of $(32 \times 24 \times 1.6) \mathrm{mm} 3$ and fabricated on an FR-4 epoxy substrate having relative dielectric constant $\varepsilon_{-} \mathrm{r}=4.3$, loss tangent tan $(\delta)=0.002$ and the feed line used has chara acteristic impedance of $50 \Omega$ and added the triangle notch structure. Thus notch can achieve maximal additional enhancement impedance bandwidth are (3.679- 6.578) GHz, (13.84-25.142) GHz, (29.807-37.618) GHz and the gain 8dBi. The antenna array performance was modified by inserting stubs transition in feeding Microstrip line to reducing mutual coupling achieve impedance bandwidth (when $\mathrm{S} 11 \leq-10 \mathrm{~dB}$ ). The modified antenna was designed to be used for wireless communication application. The simulation results are obtained using CST software.
\end{abstract}

Copyright () 2019 Institute of Advanced Engineering and Science. All rights reserved.

\section{INTRODUCTION}

The communication system request, for extra bandwidth, concentration and higher decision to give birth to the next generation of mobile communication. Microstrip antennas used in different application such as communications, radar, mobile, satellite, GPS as it tools up greater mobility. It has a feature of good bandwidth and easy integration with another scheme component. However low impedance bandwidth, low gain, low efficiency are some of the determination [1]. In command, to outdo high spread lack take place with mm-wave wide bands of the antenna, steady radiation feature, and rise again desired elliptical antenna could be a suitable filter for wide bandwidth communication application, simple to manufacture, and lightweight feature [2].

The gain afflicted can be by used metamaterial, dielectric constant, and parasitic elliptical patch for the gain increase while array construction is typically applied to realize gain [3].

The inevitable, the problem in array purpose which is how to resolve the discrepancy between the mutual coupling and the side lobe of the elements. High side lobe will reason the lowering of antenna radiation execution and rise conjunction will reason retrogression considerably on the bandwidth and antenna gain [4] The low side lobe can only understand lowering space, among the elements. Thus, can be a requirement, the conjunction lowering in case of close space. Lately, solutions on mutual conjunction lowering are suggested, to get better the radiation execution of antenna arrays [5]. In [6], There are two designed microstrip antennas printed by utilizing metamaterial loading technicality to decrease mutual conjunction. A parasitic isolator printed between two antennas is used to reduce the reciprocal conjunction through dominant the polarization of the conjunction field [7]. 
The antenna array is a complete portion system of the smart antenna. The designed array elements of the smart antenna are desirable to realize beamform for a given application a systematic arrangement, of set beaming elements is called an array size of the array and slot proportionally increase with a gain of the antenna two process to increases the slot size of the array due to increase number of elements. This wattle lobes power efficiency to increase due to wattle lobes entire the signal transmitted is equal to the sum and the reradiated signal from elements similarly so induced the current on the antenna element reradiates. The electromagnetic field which must be received by other neighboring elements in the array such mutual conjunction effect the generally seen as a disturbance which retrogrades the implementation of the array. Two kinds of conjunction restitution methods: Conventional Mutual Impedance (CMI) and Receiving Mutual Impedance (RMI) methods are prevalent [8].

\section{THEORY OF ELLIPTICAL ARRAY ANTENNA}

The matrix process for array antenna design generally outcome in a set of desired feed voltages that mill supply a given desirable set of execution feature Resultant new multimedia applications for mobile users. Suggests a method of this communication application for designing a simple feed network to supply the required set of excitation voltages. Little attention has the given to this problem in the literature [1], S. Satrusallya and M. N. Mohanty, [2], S. Zhu, H. Liu, Z. Chen, and P. Wen, [2], I. Gharbi, R. Barrak, M. Menif, and H. Ragad. The method suggested here the required number of stubs or matching elements the substantially reduced in comparison to this problem in the literature.

\subsection{Analysis of Mutual Coupling to Array Antenna}

For $\mathrm{N}$ antenna array with receiving signal at the kth antenna element $\mathrm{V}_{\mathrm{k}}$ can be expressed as the received terminal voltage:

$$
V_{K}=U_{K}+W_{K}
$$

Where $\mathrm{U}_{\mathrm{k}}$ to the received voltage.

And $\mathrm{W}_{\mathrm{k}}$ coupled voltage respectively.

The coupled voltage $\mathrm{W}_{\mathrm{k}}$ in (1) of the written as:

$$
W_{K}=Z_{t}^{K_{1}} I_{1}+Z_{t}^{K_{2}} I_{2} \ldots \ldots+Z_{t}^{K(K-1)} I_{K-1}+Z_{t}^{k(K-1)} I_{K+1}
$$

where $Z_{k}$ the receiving mutual impedance.

The terminal current $I_{i}$ at the $i$ th antenna element given by:

$$
I_{i}=\frac{V_{t}}{Z_{L}} \text { where } i=1,2, \ldots, \mathrm{N}
$$

The terminal load impedance $Z_{L}$ of the antenna elements. Placing (2) and (3) into (1), we have:

$$
V_{K}=U_{K}+Z_{t}^{K_{1}} \frac{V_{1}}{Z_{L}}+Z_{t}^{K_{2}} \frac{V_{2}}{Z_{L}}+\cdots+Z_{t}^{K(K-1)} \frac{V_{K-1}}{Z_{L}}+\cdots+Z_{t}^{K v} \frac{V^{N}}{Z_{L}}
$$

The relationship among uncoupled voltages $U_{k}$ and the received voltages $V_{k}$ as we write in a matrix as:

$$
\left[\begin{array}{c}
U_{1} \\
U_{2} \\
\cdot \\
\cdot \\
\cdot \\
\cdot U_{N}
\end{array}\right]_{1 * N}=\left[\begin{array}{cccc}
1 & \frac{z_{t}^{12}}{z_{L}} & \cdots \cdots & \frac{z_{t}^{1 N}}{z_{L}} \\
\frac{z_{t}^{21}}{z_{L}} & 1 & \cdots \cdots & \frac{z_{2 N}}{z_{L}} \\
\cdots \cdots & \cdots & & \cdots \cdots \\
\cdots \cdots & \frac{z_{t}^{N 2}}{z_{t}^{N 1}} & & \cdots \cdots \\
z_{L} & & \cdots \cdots & 1
\end{array}\right]_{N * N}\left[\begin{array}{c}
V_{1} \\
V_{2} \\
\cdot \\
\cdot \\
\cdot \\
V_{N}
\end{array}\right]_{1 * N}
$$

Combined reciprocal conjunction the readily measured immediately, or from S-parameters, the relationship among the terminal voltage and current we given by:

$$
V_{1}=I_{1} Z_{K, 1}+I_{2} Z_{K, 2}+\cdots I_{i} Z_{K, i}+I_{K} Z_{K, K}+\cdots I_{N} Z_{K, N}+I_{0 K}
$$


where $\mathrm{Z}_{\mathrm{L}}$ impedance is given the relationship between voltage and current by:

$$
Z_{L}=-\frac{V_{i}^{t}}{I_{1}^{t}}
$$

The relation among the open circuit voltages and terminal voltages we wrote as

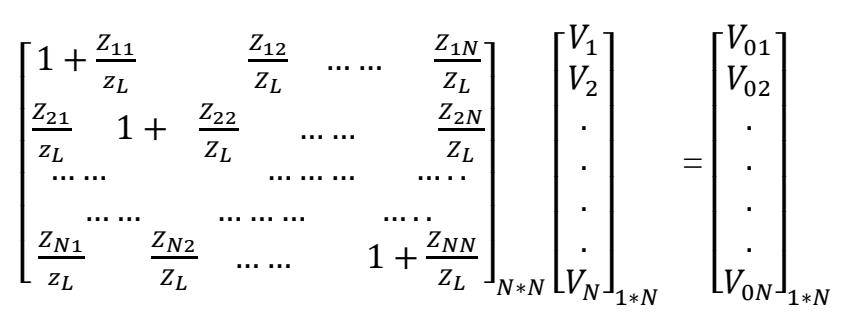

The ratio of the coupled voltage between two antennas is load $\mathrm{Z}_{\mathrm{L} 2}$ represent the receiving reciprocal impedance $[9,10]$.

$$
Z_{t}^{12}=-\frac{\left(V_{1}-U_{1}\right)}{I_{2}}
$$

\subsection{Geometry Elliptical Antenna Array Factor}

The elliptical antenna array of the geometry with the origin as the center is shown in Figure 1[11]. As shown in (10) shown is given array factor as:

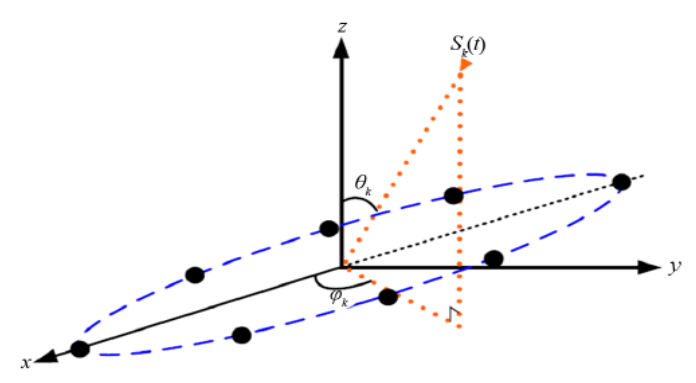

Figure 1. There is an elliptical antenna in XY-plane

$$
A F(\theta, \varnothing)=\sum I_{n} \exp \left[K \sin (\theta)\left(\operatorname{acos}\left(\theta_{n}\right) \cos (\varnothing)+b \sin \left(\emptyset_{n}\right) \sin (\varnothing)+\alpha_{n}\right)\right]
$$

$I_{n}=$ The amplitude of excitation.

$\alpha_{n}=$ The phase of the $\mathrm{n}$ th element.

$\Theta=$ The elevation angle from z-axis.

$\emptyset_{n}=$ The azimuth angle measured from the x-axis for the $n$-th element.

$a, b=$ semi-major and minor axes respectively.

$e=$ eccentricity of the elliptical array and is 0.5

$$
\alpha_{n}-K \sin \left(\theta_{0}\right)\left(\operatorname{acos}\left(\theta_{n}\right) \cos \left(\emptyset_{0}\right)+b \sin \left(\emptyset_{n}\right) \sin \left(\emptyset_{0}\right)+\alpha_{n}\right)
$$

$\theta_{0}=90^{\circ}, \emptyset_{0}=0^{\circ}$.

$N=$ no of elements is 2

Area $(A)=\prod a b$

$$
\operatorname{cicumference}(e)=\prod(3(a+b)-\sqrt{(3 a+b)(a+3 b)})
$$

The current distribution of the shape will the modeled as follows [12].

$$
J_{s}=\hat{Z} I_{o} / \pi r_{o}
$$


Where $I_{o}$ is the total current flowing on the cylinder of diameter $r_{o}$

The shape of the elliptical patch is consist of two circular patches with radii attach to the major and minor axes, the total currents on the patch are the sum of currents on the two circular patches.

$$
\begin{aligned}
& J_{1(\rho, \phi)}=\sum_{n=1}^{\infty} a_{n}^{1} F_{n}^{1}(\rho, \phi) \\
& J_{2(\rho, \phi)}=\sum_{n=1}^{\infty} b_{n}^{1} F_{n}^{2}(\rho, \phi)
\end{aligned}
$$

Where $F_{n}^{1}(\rho, \phi)$ and $F_{n}^{2}(\rho, \phi)$ are the requisite functions of the unknown currents on the each circular patch and $a_{n}^{1}$ and $b_{n}^{1}$ are complex coefficients of the unknown currents on each circular patch. [13]. The engagement mode needs private types of basic functions to model the current in the vicinity of the probe patch section and can be generally negligible for thin substrates but cannot be ignored for thick substrates. Therefore, engagement mode is assumed to exist on the fictitious small circle and replaced by the coaxial waveguide with an inner radius $r_{0} / 2$ and outer radius $r$. The total currents on the patch and probe are expanded into.

$$
J_{s(\rho, \phi)}=\sum_{n=1}^{N} a_{n} F_{n}(\rho, \phi)+\sum_{m=1}^{M} b_{m} F_{m}(\rho, \phi)+\left(F_{\text {at tach }}\right)
$$

Where $F_{n}(\rho, \phi)$ and $F_{m}(\rho, \phi)$ is are the basic functions on the patch and on the probe respectively and, $\left(F_{a t \text { tach }}\right)$ is the attachment mode[14] For more information on the subject see Refrence[2, 15-22].

\section{DESIGN SINGLE AND ARRAY ANTENNA AND SIMULATION RESULT}

The geometry of the proposed single and array antennas for wireless communications application the shown in Figure 2(a,b). The patch of the antenna is in the shape of an ellipse, and its dimensions illustrated in Table (1). The antenna designed on a compact FR-4 substrate with relative Permittivity $\left(\varepsilon_{\mathrm{r}}\right)$ of 4.3 having dimensions $(17 \times 14 \times 1.6) \mathrm{mm}^{3}$. and was implemented array antenna having dimensions $(32 * 24 * 1.6) \mathrm{mm}^{3}$ to improve the gain and operated mm-wave wireless communication. The proposed single and array antenna geometry simulated in CST, and the bandwidth with reflection Coefficient $\left(\mathrm{S}_{11}\right)$ observed shown in Figure 3(a,b) and improved the gain from the single antenna is around (6.8) dBi to (8) dBi for array antenna as shown in Figure 4(a,b).

Table 1. Design Parameters

\begin{tabular}{cccccc}
\hline Parameters & Values in $\mathrm{mm}$ & Parameters & Values in $\mathrm{mm}$ & Parameters & Values in $\mathrm{mm}$ \\
\hline $\mathrm{W}$ & 14 & $\mathrm{~L}$ & 17 & $\mathrm{H}$ & 1.6 \\
$\mathrm{Rx}$ & 6 & $\mathrm{Ry}$ & 5 & $\mathrm{Wf}$ & 2.8 \\
$\mathrm{Lf}$ & 5 & $\mathrm{XS}$ & 1 & YS & 2 \\
RCS & 2.2 & LG & 4 & WG & 14 \\
\hline
\end{tabular}

The proposed antenna has practically manufactured and shown in Figure 5, and good results have been obtained compared to the simulation results shown in Figure 6. The Practical Reflection Coefficient Versus frequency to $20 \mathrm{GHz}$ as shown in Figure 7 . The slight difference in process results and simulation is due to the feeder soldering as well as the connections of the vector network analyzer.

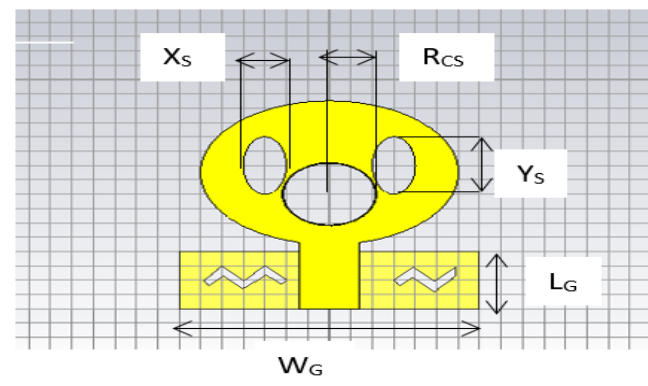

(a)

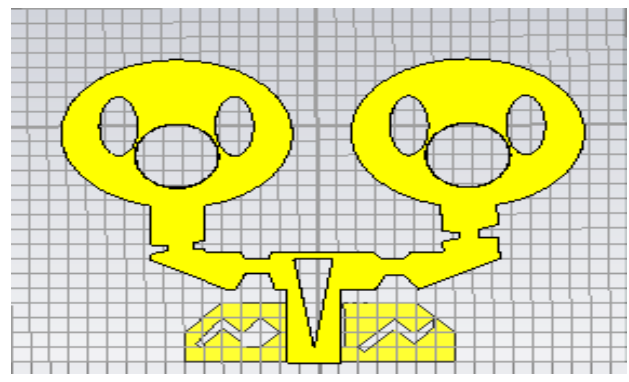

(b)

Figure 2. The Elliptic antenna (a) single antenna, and (b) array antenna 




(a)

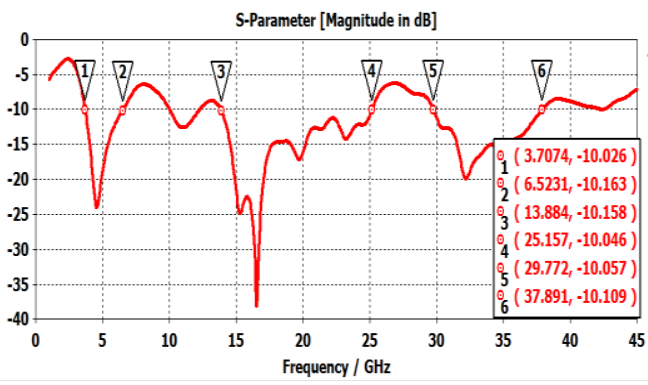

(b)

Figure 3. The reflection coefficient versus frequency (a)single and (b) array antenna

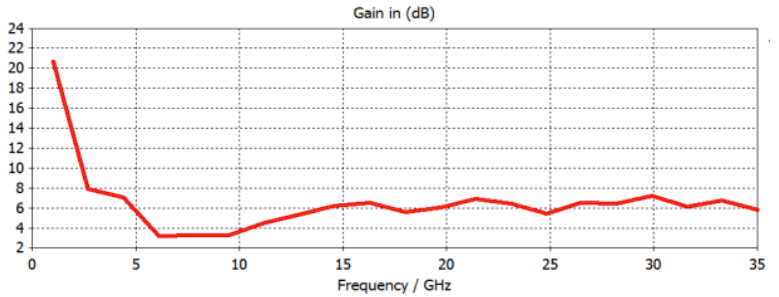

(a)

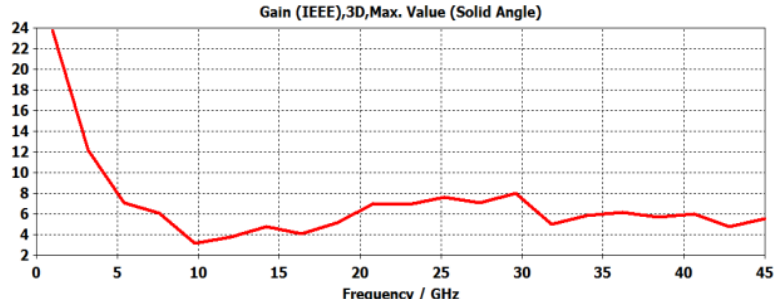

(b)

Figure 4. Variation of gain with the frequency of the proposed (a) single and (b) array antenna

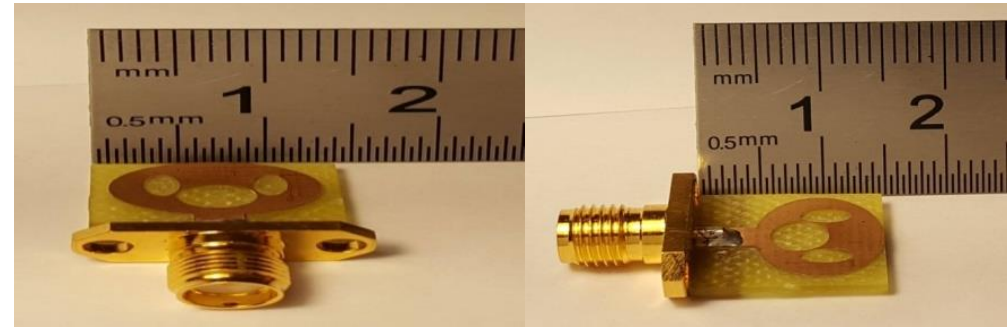

Figure 5. The practical proposed single antenna

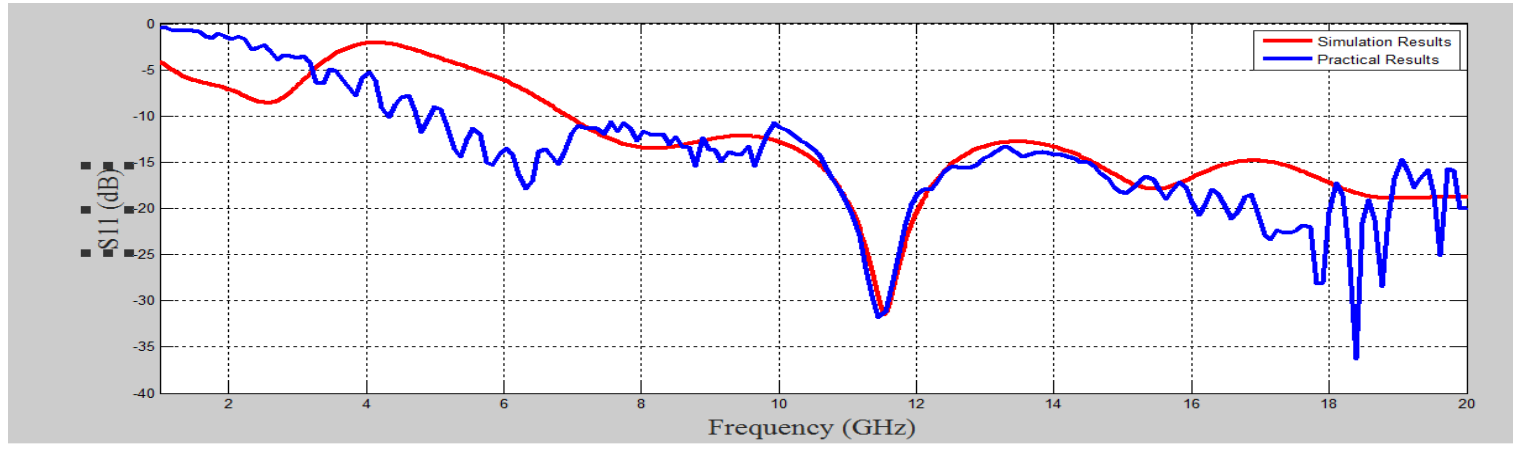

Figure 6. The compere reflection coefficient versus frequency of results simulation and practical 


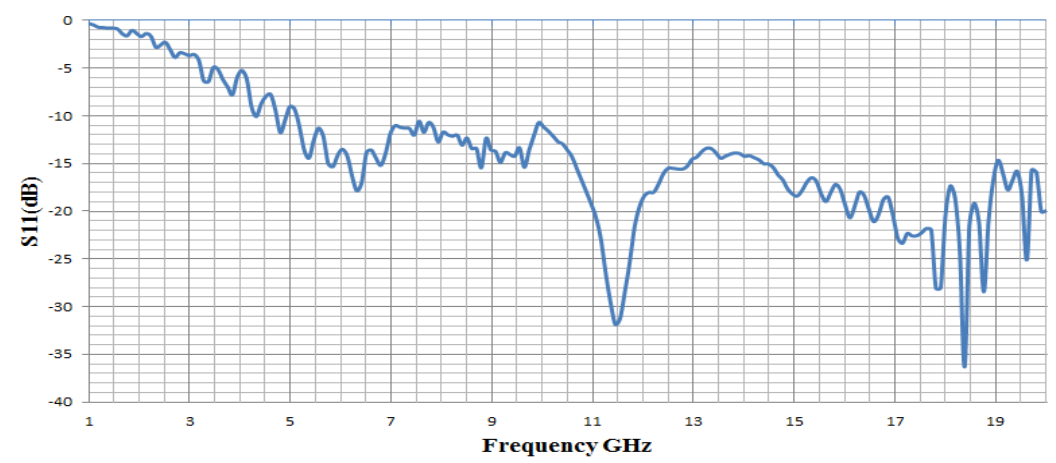

Figure 7. The reflection coefficient versus frequency of practical results

The group time delay of the single and array antenna designed should be able to transmit electrical pulse with minimum distortion, calculated of the proposed antenna is around to zero with variation is than $0.1 \mathrm{nsec}$ due to the frequency band as shown to Figure 8. The voltage standing wave ratio (VSWR) is also less than $\leq 2$ as shown in Figure 9 so that the VSWR is the ratio of maximum voltage or current to minimum voltage or current at any point it considers as a measure for the mismatch between the line and the load. The final antenna has an impedance bandwidth real and imaginary parts of the input impedance is shown in Figures 10 and 11 respectively.

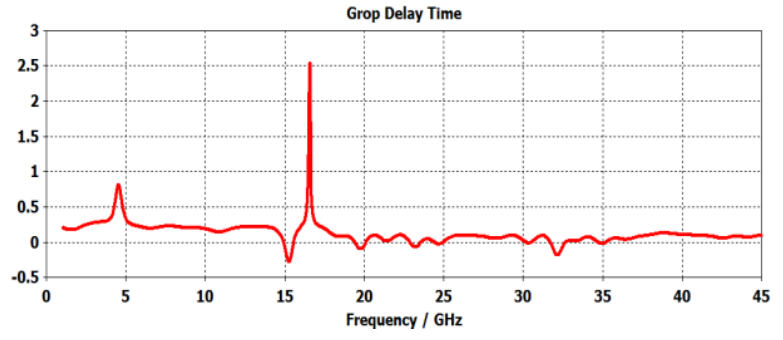

Figure 8 . The group time delay to the proposed antenna

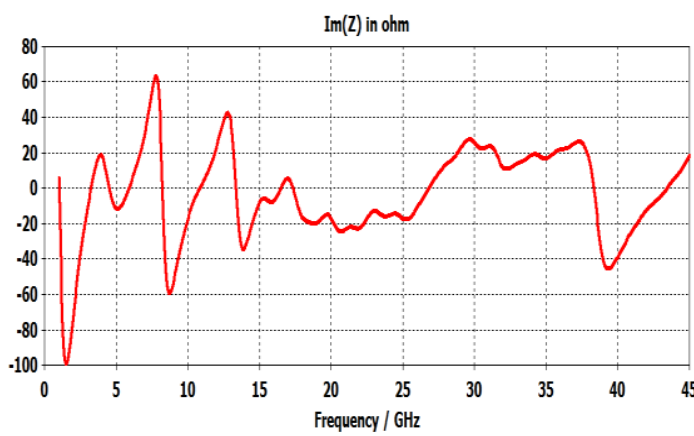

Figure 10. The real impedance of the proposed array antenna

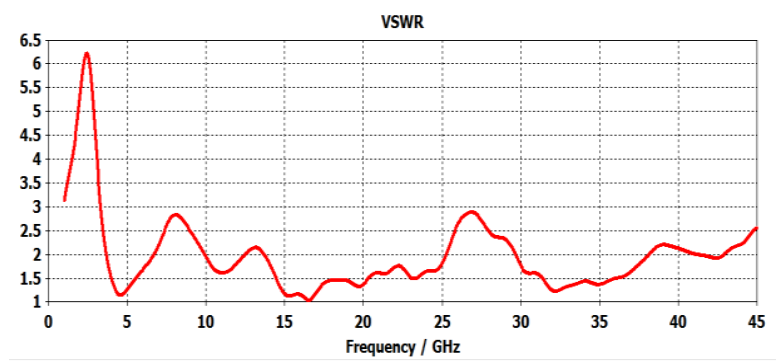

Figure 9. The VSWR of the proposed antenna

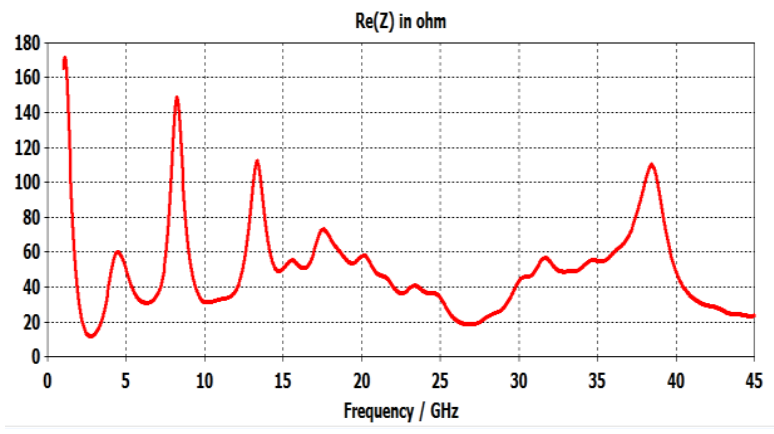

Figure 11. The imaginary impedance of the proposed array antenna

The result 2D/3D as shown in Figure 12 show to E-field and $\mathrm{H}$-field distribution for frequency 15.5GHz and $30 \mathrm{GHz}$ Figure $12(\mathrm{a}, \mathrm{b}, \mathrm{c}, \mathrm{d})$ respectively and current surface distribution in Figure $9(\mathrm{e}, \mathrm{f})$ and Figure $9(\mathrm{~g}, \mathrm{~h})$ show far-field polar form and gain pattern in frequency $15.5 \mathrm{GHz}$ is $3.148 \mathrm{~dB}$ and frequency $30 \mathrm{GHz}$ is $3.88 \mathrm{~dB}$. 

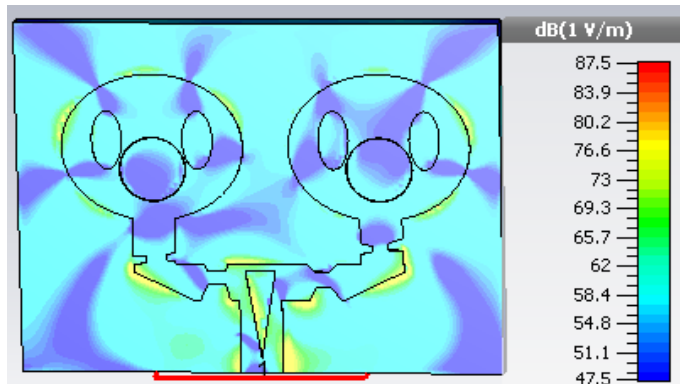

(a). E-Field distribution at $\mathrm{f}=15.5 \mathrm{GHz}$
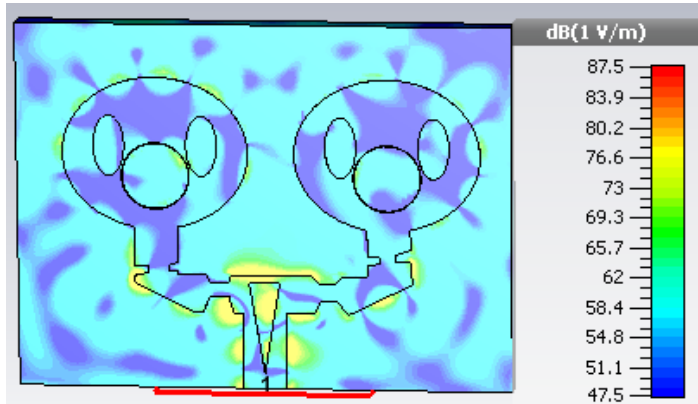

(c). E-Field distribution at $\mathrm{f}=30 \mathrm{GHz}$

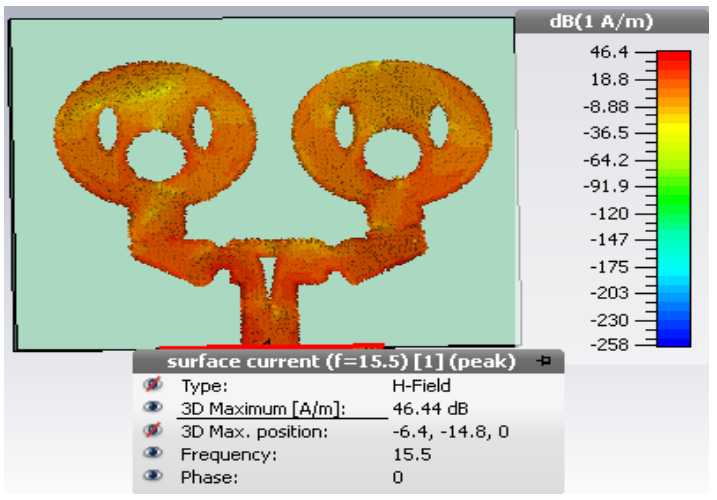

(e). Current surface distribution at $\mathrm{f}=15.5 \mathrm{GHz}$

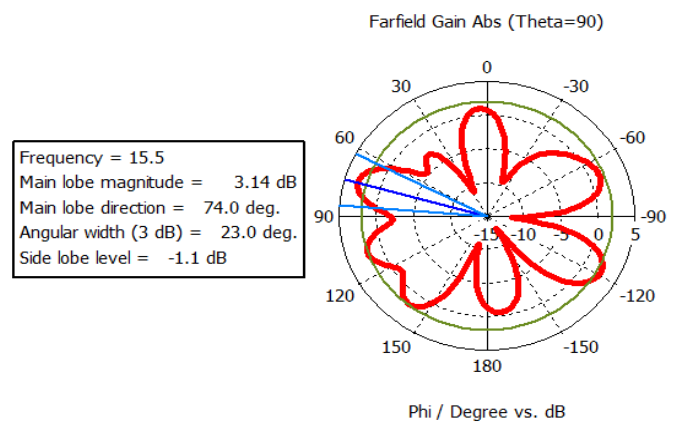

(g). Farfield polar form at $\mathrm{f}=15.5 \mathrm{GHz}$

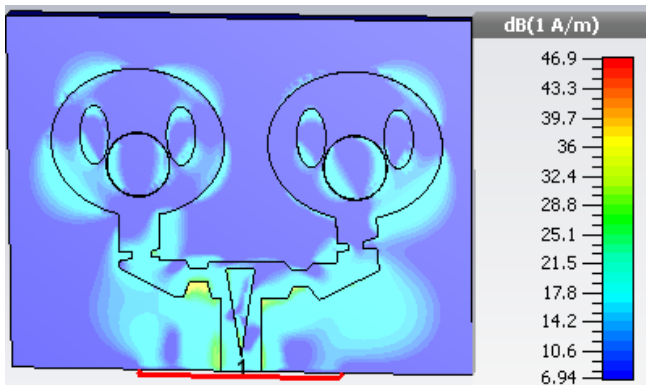

(b). H-Field distribution at $\mathrm{f}=15.5 \mathrm{GHz}$

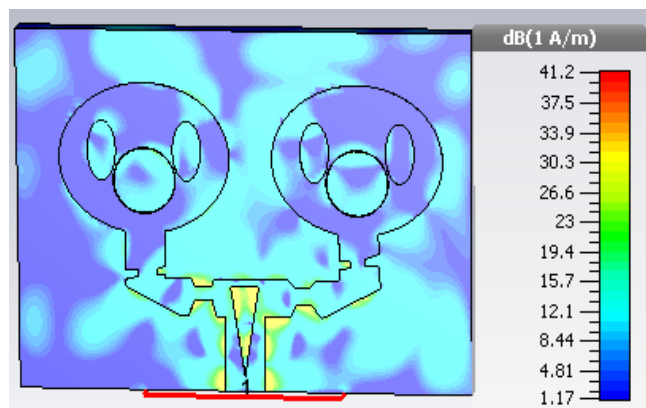

(d). H-Field distribution at $\mathrm{f}=30 \mathrm{GHz}$

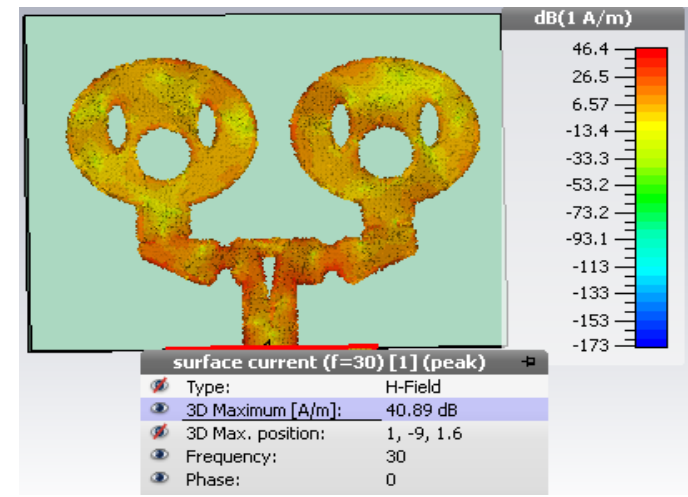

(f). Current surface distribution at $\mathrm{f}=30 \mathrm{GHz}$

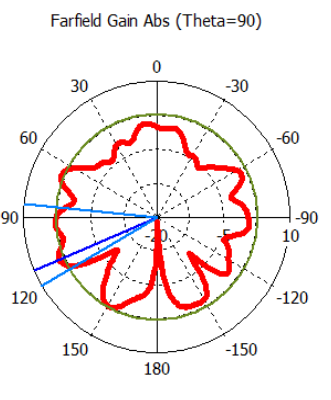

Phi / Degree vs. dB

(h). Farfield polar form at $\mathrm{f}=30 \mathrm{GHz}$

Figure 12. Farfield 2D/3D results[a, b, c, d, e, f, g, h]

The failed broadband to the proposed antenna as shown in Figure 13 shows the total gain pattern with $3 \mathrm{~dB}$ angular width is $19.9 \mathrm{~dB}$ 


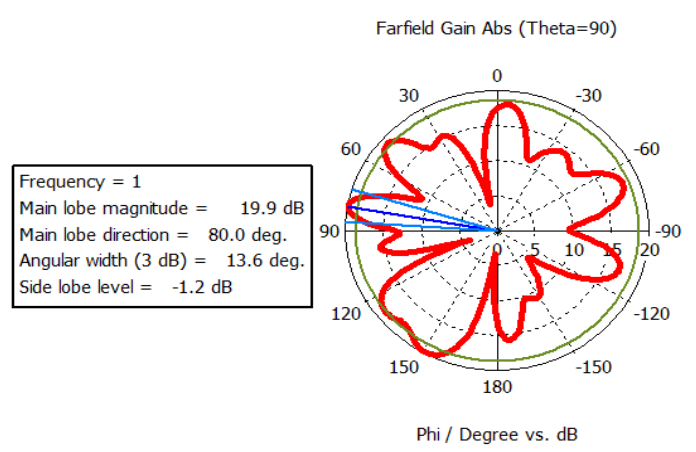

Figure 13. Gain pattern for fairfield broadband to the proposed antenna

\section{CONCLUSION}

A new broadband microstrip elliptical single and array antenna in suggested and studied with optimum parameters using an FR-4 substrate with relative dielectric constant $\varepsilon_{r}=4.3$. The bandwidth of singthe le antenna is (6.95-30.94) $\mathrm{GHz}$ which covers many wireless applications (such as 5G mobile communications and maximum gain of $6.8 \mathrm{dBi}$. It is also noted that the slots in the ground improve the bandwidth when as the slots in the patch modify the gain, and fabricate the proposed antenna and test it using the vector network analyzer (VNR) and compare the simulation and test results. The antenna has a good the bandwidth frequency is $24 \mathrm{GHz}$. Also the, gainthe can be improved by proposing by implemrnted antenna array is $8 \mathrm{dBi}$, with a $2 \mathrm{D} / 3 \mathrm{D}$ total gain broadband pattern with $3 \mathrm{~dB}$ angular width is $19.9 \mathrm{dBi}$. all these suggestion are required to make the proposed antenna to serve the new generations of mobile and wireless communications applications. The size of the proposed elliptical array antenna is $(32 \times 24 \times 1.6) \mathrm{mm}^{3}$.

\section{REFERENCES}

[1] S. Satrusallya and M. N. Mohanty, "Design of an array antenna for a 5G wireless network with enhanced bandwidth," in Infocom Technologies and Unmanned Systems (Trends and Future Directions)(ICTUS), 2017 International Conference on, 2017, pp. 1-5.

[2] S. Zhu, H. Liu, Z. Chen, and P. Wen, "A Compact Gain-Enhanced Vivaldi Antenna Array With Suppressed Mutual Coupling for 5G mmWave Application," IEEE Antennas and Wireless Propagation Letters, vol. 17, pp. 776-779, 2018.

[3] B. B. N. Q. Elias, "Analysis of different structures of patch antennas," Eastern Mediterranean University (EMU)Doğu Akdeniz Üniversitesi (DAÜ), 2014.

[4] K. Da Xu, Y. H. Zhang, R. J. Spiegel, Y. Fan, W. T. Joines, and Q. H. Liu, "Design of a stub-loaded ring-resonator slot for antenna applications," IEEE Transactions on Antennas and Propagation, vol. 63, pp. 517-524, 2015.

[5] I. T. Nassar and T. M. Weller, "A novel method for improving antipodal Vivaldi antenna performance," IEEE Transactions on Antennas and Propagation, vol. 63, pp. 3321-3324, 2015.

[6] H.-X. Xu, G.-M. Wang, and M.-Q. Qi, "Hilbert-shaped magnetic waveguided metamaterials for electromagnetic coupling reduction of microstrip antenna array," IEEE Transactions on Magnetics, vol. 49, pp. 1526-1529, 2013.

[7] Y.-F. Cheng, X. Ding, W. Shao, and B.-Z. Wang, "Reduction of mutual coupling between patch antennas using a polarization-conversion isolator," IEEE Antennas and Wireless Propagation Letters, vol. 16, pp. 1257-1260, 2017.

[8] A. V. L. N. Rao, N. B. Ankaiah, and D. R. Cheruku, "Antenna performance improvement in an elliptical array using RMI method of mutual coupling compensation," Journal of Electromagnetic Analysis and Applications, vol. 8, p. 8, 2016.

[9] H.-S. Lui, H. T. Hui, and M. S. Leong, "Investigation of direction-of-arrival estimation using uniform linear arrays with different antenna separations and array apertures," in Microwave Conference, 2008. APMC 2008. Asia-Pacific, 2008, pp. 1-4.

[10] A. L. A. K. Jassim, "The Optimality Effectiveness of Signal Amplitude on Synchronizations Using Cascading of Chaotic System," Journal of Engineering and Development, vol. 18, 2014.

[11] C. A. Balanis, " Antenna Theory: Analysis and Design. Wiley, New York.," (1997).

[12] A. Sarah, "Analysis of 5G Mobile Broadband Solutions in Rural and Remote Areas: A Case Study of Banten, Indonesia," ed, 2017.

[13] W. Ahmad, A. Tarczynski, and D. Budimir, "Design of monopole antennas for UWB applications," in Antennas and Propagation \& USNC/URSI National Radio Science Meeting, 2017 IEEE International Symposium on, 2017, pp. 2323-2324.

[14] H. Jung and C. Seo, "Analysis of elliptical microstrip patch antenna considering attachment mode," IEEE Transactions on Antennas and Propagation, vol. 50, pp. 888-890, 2002. 
[15] Y. Niu, Y. Li, D. Jin, L. Su, and A. V. Vasilakos, "A survey of millimeter wave communications (mmWave) for 5G: opportunities and challenges," Wireless Networks, vol. 21, pp. 2657-2676, 2015.

[16] M. Khan, A. Capobianco, A. Naqvi, M. Shafique, B. Ijaz, and B. Braaten, "Compact planar UWB MIMO antenna with on-demand WLAN rejection," Electronics Letters, vol. 51, pp. 963-964, 2015.

[17] N. K. Reddy, A. Hazra, and V. Sukhadeve, "A Compact Elliptical Microstrip Patch Antenna for Future 5G Mobile Wireless Communication," Transactions on Engineering \& Applied Sciences, vol. 1, pp. 1-4, 2017.

[18] V. Kolli and S. M. Reddy, "Design and performance analysis of microstrip patch antenna using different dielectric substrates," 2017.

[19] R. M. Shaaban, Z. A. Ahmed, and W. A. Godaymi, "Design and Analysis for Circular Microstrip Antenna Loaded by two Annular Rings," Global Journal of Computer Science and Technology, 2017.

[20] B. Yu, K. Yang, and G. Yang, "A Novel 28 GHz Beam-Steering Array for 5G Mobile Device With Metallic Casing Application," IEEE Transactions on Antennas and Propagation, vol. 66, pp. 462-466, 2018.

[21] A. Zaidi, A. Baghdad, A. Ballouk, and A. Badri, "Design and Optimization of a High Gain Multiband Patch Antenna for Millimeter-Wave Applications," International Journal of Electrical and Computer Engineering (IJECE), vol. 8, 2018.

[22] S. Alam, I. Surjati, A. Ferawan, and T. Firmansyah, "Design and Realization of Compact Microstrip Antenna Using Fractal Sierpinski Carpet For Wireless Fidelity Application," Indonesian Journal of Electrical Engineering and Informatics (IJEEI), vol. 6, pp. 70-78, 2018. 